\title{
Base Doping Effects on the Efficiency of Vertical Parallel Junction Solar Cells
}

\author{
Almoustapha Samoura, Oumar Sakho, Omar Faye, Aboubaker Chedikh Beye \\ Solid State Physics and Material Science Laboratory, Sciences and Technique Faculty, Cheikh Anta Diop University, Dakar, \\ Senegal \\ Email: samouraalmoustapha@yahoo.fr
}

How to cite this paper: Samoura, A., Sakho, O., Faye, O. and Beye, A.C. (2017) Base Doping Effects on the Efficiency of Vertical Parallel Junction Solar Cells. Open Journal of Applied Sciences, 7, 282-290. https://doi.org/10.4236/ojapps.2017.76023

Received: May 10, 2017

Accepted: June 20, 2017

Published: June 23, 2017

Copyright (c) 2017 by authors and Scientific Research Publishing Inc. This work is licensed under the Creative Commons Attribution International License (CC BY 4.0).

http://creativecommons.org/licenses/by/4.0/

\begin{abstract}
In this work, we present a theoretical study of a vertical parallel junction silicon solar cell under monochromatic illumination. The internal quantum efficiency (IQE) and the photovoltaic conversion efficiency are calculated, taking into account the base doping density and illumination wave-length. The main purpose of this work is to show how conversion efficiency depends on internal quantum efficiency and the dependence of the later on the base doping density.
\end{abstract}

\section{Keywords}

Vertical Junction, Doping, Internal Quantum Efficiency (IQE)

\section{Introduction}

Solar cells are semiconductor devices that are able of direct conversion of light into electricity. Since their invention in the 1950s [1] there was a very rapid growth of the production and use of solar cells. Many technologies were developed like crystalline silicon solar cells, thin films, organic solar cells, nanowire solar cells and so on with families and subfamilies.

Vertical junction solar cells also called edge-illumination solar cells [2] [3] [4] are solar cells that are illuminated parallel to the junction contrary to conventional solar cells illuminated perpendicularly to their junctions.

Vertical multijunction solar cells (VMJ) can be classified into two main families: parallel-connected junctions and series-connected junctions; in this work, we are using parallel-connected vertical junction solar cells.

Since their introduction, these devices continue to be improved to minimize both optical and electrical losses with significant increase in the conversion efficiency [5] [6]. This conversion efficiency is directly related to the internal quan- 
tum efficiency of the cell (IQE) that also reflects different recombination processes associated to the base doping density.

The IQE is defined as "the wavelength-dependent short-circuit current density as a function of wavelength". In this study, we will lay stress on the dependence of the photocurrent density, the photovoltage, the maximum output power on the base doping density and the correlations between conversion efficiency and internal quantum efficiency.

\section{Mathematical Formulation}

A schematic diagram of the vertical parallel junction silicon solar cell is given in Figure 1.

As noted before, cells are connected in a parallel manner, one emitter with another and one base to another.PN junction. The metal contacts are made on the lateral sides of the sub-cells so there is no shading. The width of the sub-cell can be made smaller [7] and then the series resistance will be also reduced. Under illumination, there are the three major phenomena that occur inside a solar cell: carrier generation, re-combination and drift/diffusion. We consider the base region of the VMJ cell, neglecting the emitter given its contribution is very low compared to that of the base. We also assume a quasi-neutral p-type base (QNB) [8], low injection condition and no lateral effect; then, the principal transport mechanism remains a one dimension diffusion of minority carriers. In steady state, we then have:

$$
D_{n} \cdot \frac{\partial^{2} n(x)}{\partial x^{2}}-\frac{n(x)}{\tau_{n}}=-g(z) .
$$

with:

$g(z)=\alpha \cdot(1-R) \cdot I \cdot \mathrm{e}^{-\alpha \cdot z}$ being the carrier generation rate under monochromatic illumination at the depth $z$ in the base [9], $I$ is the incident flux, $n(x)$ the minority carrier density in the base.

$\alpha$ is the absorption coefficient [10], $R$ is the reflexion coefficient at the wavelength $\lambda, D_{n}$ the diffusion coefficient traducing the ability of the carrier to diffuse into the base. This coefficient depends strongly on the base doping density and is

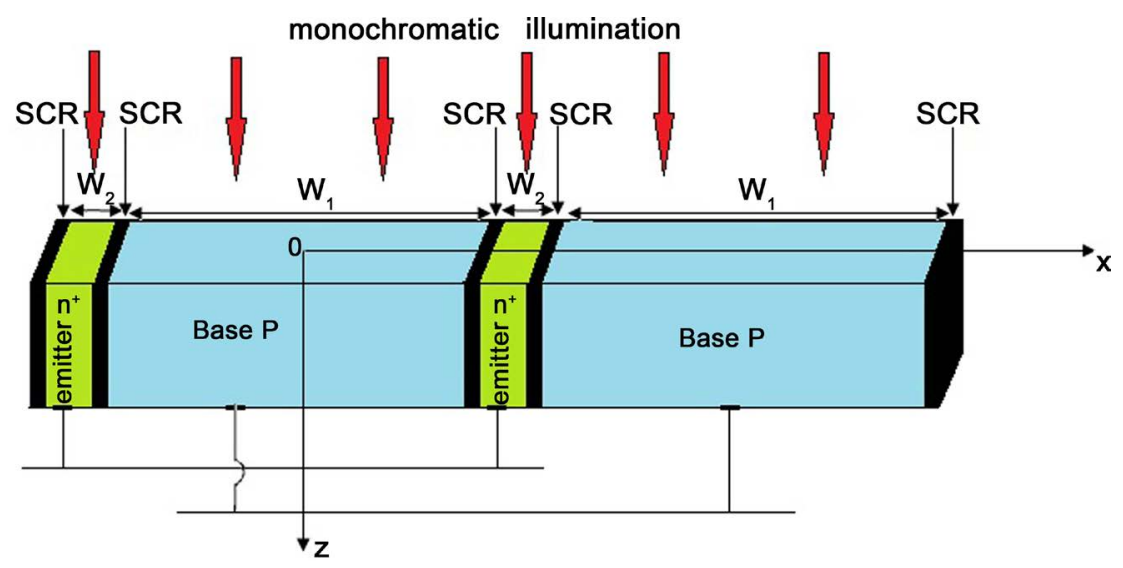

Figure 1. Vertical parallel junction solar cell. 
given by the following expression [11]:

$$
D_{n}\left(N_{B}\right)=\frac{1350 \cdot V_{T}}{\sqrt{1+\frac{81 \cdot N_{B}}{N_{B}+3.2 \times 10^{18}}}} .
$$

The minority carrier lifetime $\tau_{n}$ in the base also depend on the base doping density and can be expressed as:

$$
\tau_{n}\left(N_{B}\right)=\frac{12}{\sqrt{1+\frac{N_{B}}{5 \times 10^{16}}}} .
$$

The diffusion length $L_{n}$ being the mean distance covered by minority carrier before they recombine is related to both carrier lifetime and diffusion coefficient and then to base doping density. This dependence can be written in the form:

$$
L_{n}\left(N_{B}\right)=\sqrt{D_{n}\left(N_{B}\right) \cdot \tau_{n}\left(N_{B}\right)} .
$$

\subsection{Excess Minority Carrier Density in the Base}

Carrier generation, recombination and drift/diffusion are the three major phenomena that occur inside a solar cell under illumination. If we consider only the base region of the cell, neglecting the emitter since its contribution is very low in comparison to that of the base and also assume a quasi-neutral p-type base (QNB) in low injection condition and no lateral effect, then, the principal transport mechanism remain a one dimensional diffusion of minority carriers (electrons).

In steady state we have:

$$
\frac{\partial n(x)}{\partial x^{2}}-\frac{1}{L_{n}^{2}\left(N_{B}\right)} \cdot n(x)=\frac{g(z)}{D_{n}\left(N_{B}\right)} .
$$

The solution of Equation (5) can be written as:

$$
n(x)=A_{1} \cdot \cosh \left(\frac{x}{L_{n}}\right)+B_{1} \cdot \sinh \left(\frac{x}{L_{n}}\right)+\frac{L_{n}^{2}}{D_{n}} \cdot \alpha_{t} \cdot I_{t} \cdot\left(1-R_{t}\right) \cdot \mathrm{e}^{-\alpha \cdot z} .
$$

Coefficients $A_{1}$ and $B_{1}$ are determined considering the two following boundary conditions:

- At the junction $\left(x=-W_{1} / 2\right)$ :

$$
\left.\frac{\partial n(x)}{\partial x}\right|_{x=-\frac{W_{1}}{2}}=\left.\frac{S_{f}}{D_{n}} \cdot n(x)\right|_{x=-\frac{W_{1}}{2}} .
$$

With $S_{f}$ being the junction dynamic velocity corresponding to the flow of carrier through the junction.

- In the middle of the base $(x=0)$ :

$$
\left.\frac{\partial n(x)}{\partial x}\right|_{x=0}=0 .
$$

Giving these two boundary conditions and Equation (6) and after some calcu- 
lations, the final expression of the minority carrier density is written as:

$$
n(x)=A_{1} \cdot \cosh \left(\frac{x}{L_{n}}\right)+\frac{L_{n}^{2}}{D_{n}} \cdot \alpha_{t} \cdot\left(1-R_{t}\right) \cdot I_{t} \cdot \mathrm{e}^{-\alpha \cdot z} .
$$

\subsection{Photocurrent Density and Photovoltage}

Based on the excess minority carrier density, we can derive both photocurrent density $J_{n}$ and photovoltage respectively as:

$$
J_{p h}=\left.2 \cdot q \cdot D_{n} \cdot \frac{\partial n(x)}{\partial x}\right|_{x=\frac{-W_{1}}{2}} .
$$

with $q$ the elementary charge ; the factor 2 comes from the presence of the two junctions on both sides of the base. For the photovoltage, thanks to Boltzmann's law, we have:

$$
V_{P h}=V_{T} \cdot \ln \left(\frac{N_{B} \cdot n\left(\frac{-W_{1}}{2}\right)}{n_{i}^{2}}+1\right) .
$$

with $n_{i}$ the intrinsic concentration and $V_{T}$ the thermal voltage:

$$
V_{T}=\frac{k \cdot T}{q} .
$$

where $k$ is the Boltzmann's constant and $T$ the temperature.

\subsection{Output Power}

When the solar cell is illuminated, it can deliver the power $P$ given by:

$$
P=V_{p h} \cdot J_{p h} .
$$

The power loss in the intrinsic diode is neglected given it is negligible compared to the whole power.

\subsection{Internal Quantum Efficiency}

The measurement of the quantum efficiency of solar cells is generally used to quantify recombination losses. The internal quantum efficiency $R_{Q}$ of a solar cell is defined as the fraction of collected electron/hole pairs per photon of wavelength that enters the solar cell. The commonly applied analysis uses a plot of the inverse quantum efficiency versus the inverse of the absorption; in this study, it is the dependence on the base doping that is analyzed and how it is related to the conversion efficiency.

The internal quantum efficiency is expressed as:

$$
R_{Q}=\frac{J_{p h}}{A \cdot q \cdot I \cdot(1-R)} .
$$

\section{Results and Discussions}

Considering the above mathematical formulation, we performed simulations for 
various base doping densities and also different illumination wavelengths. The obtained results are presented below.

\subsection{Minority Carrier Density}

We present on Figure 2 the excess minority carrier density versus base doping density for various illumination wavelengths.

Figure 2 shows that excess minority carrier density in the base slightly increases firstly until a base doping density of about $10^{17} \mathrm{~cm}^{-3}$. Above that doping density, carrier density decreases very significantly. Indeed, below $10^{17} \mathrm{~cm}^{-3}$, an increase of base doping leads to a little increase in base doping but above $10^{17}$ $\mathrm{cm}^{-3}$ recombination processes becomes more and more predominant, leading to a decrease of the carrier density as observed.

\subsection{Photocurrent Density}

In the following figures, we plotted the photocurrent density versus base doping density for various illumination wavelengths. In Figure 3 we considered wavelength range of $0.66 \mu \mathrm{m}$ to $0.78 \mu \mathrm{m}$ and in Figure 4 we considered wavelength range of $0.8 \mu \mathrm{m}$ to $0.92 \mu \mathrm{m}$.

These figures show clearly that photocurrent density is more interesting while the base doping density is of the order of $10^{17} \mathrm{~cm}^{-3}$ and below. These curves also show that there is a limit to base doping density as we can observe a very marked decrease of the photocurrent densities near and above $10^{17} \mathrm{~cm}^{-3}$. Given that recombination activities (centers) are directly related to base doping density that is why photocurrent density is so sensitive to base doping density.

Below $0.8 \mu \mathrm{m}$, photocurrent density increases with illumination wavelength contrary to wavelengths above $0.8 \mu \mathrm{m}$; this could be explained by the illumina-

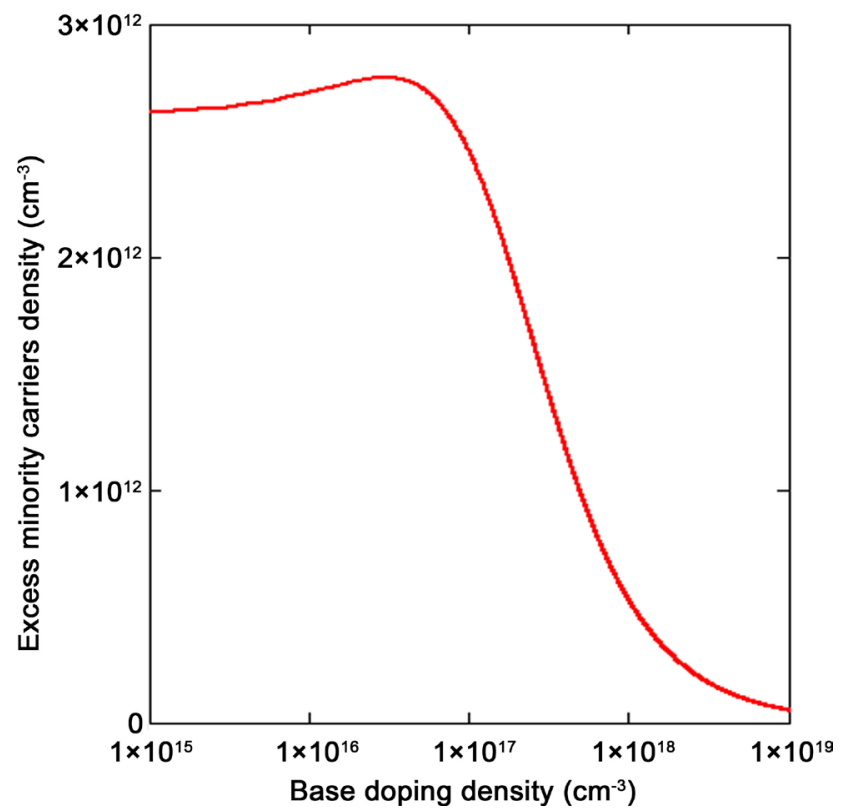

Figure 2. Excess minority carrier density versus base doping $\left(D_{n}=26 \mathrm{~cm}^{2} / \mathrm{s}, Z=200 \mu \mathrm{m}\right.$, $\left.x=200 \mu \mathrm{m}, S_{f}=4 \times 10^{4} \mathrm{~cm} / \mathrm{s}\right)$. 


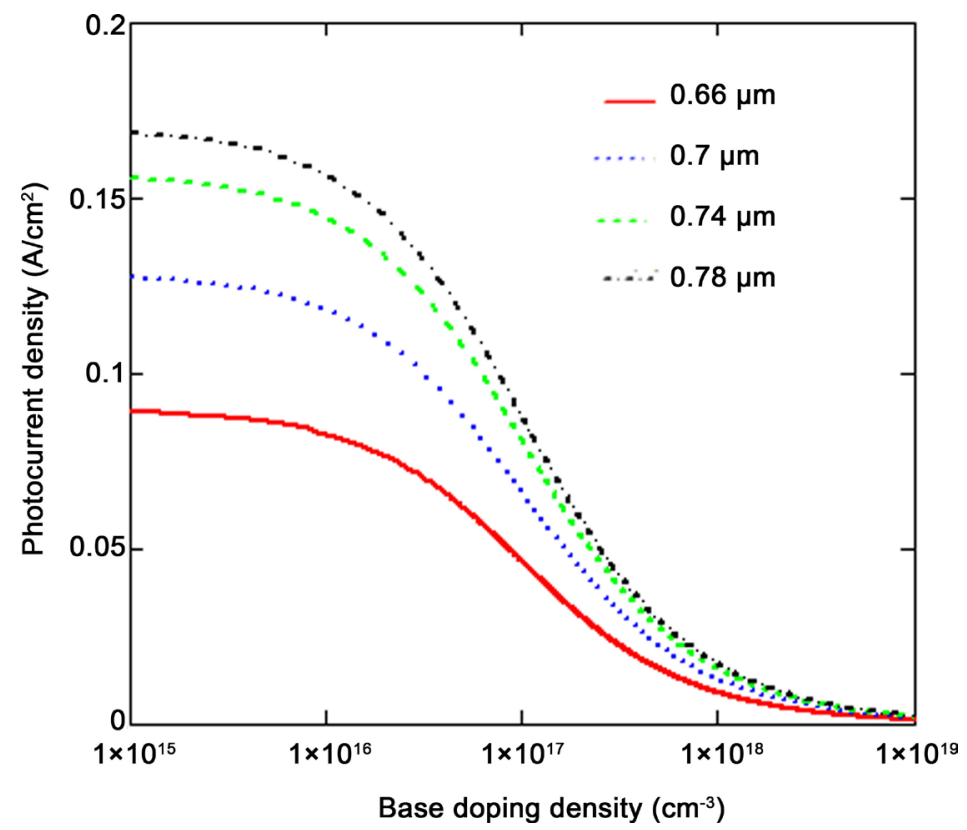

Figure 3. Photocurrent density versus base doping for different wavelengths $\left(D_{n}=26\right.$ $\left.\mathrm{cm}^{2} / \mathrm{s}, Z=200 \mu \mathrm{m}, S_{f}=3 \times 10^{3} \mathrm{~cm} / \mathrm{s}\right)$.

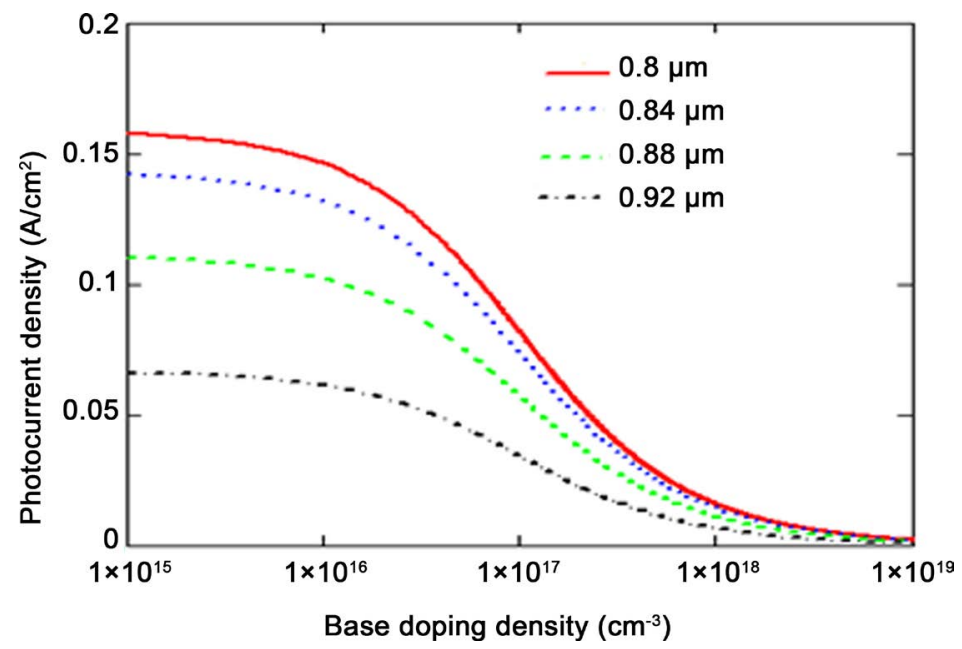

Figure 4. Photocurrent density versus base doping for various wavelengths $\left(D_{n}=26\right.$ $\mathrm{cm}^{2} / \mathrm{s}, z=200 \mu \mathrm{m}, S_{f}=3 \times 10^{3} \mathrm{~cm} / \mathrm{s}$ ).

tion spectrum with lower wavelengths associated to higher energy, generating more carriers in the base of the solar cell.

\subsection{Maximum Output Power}

The maximum output power is computed versus base doping density and the results are presented in Figure 5.

We can observe an increase of the maximum output power for lower base doping density until $10^{16} \mathrm{~cm}^{-3}$, and above that value, we have a very marked decrease as for the excess minority carrier density. This confirm the fact that there is an optimum doping density for the base and above that doping density the performance of the solar cell decreases significantly. 


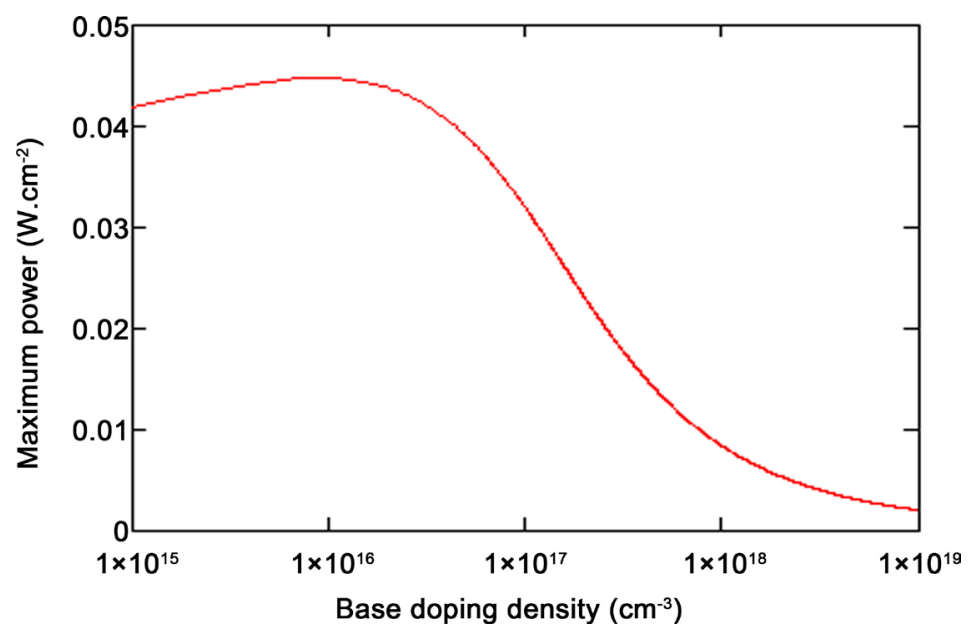

Figure 5. Maximum power versus base doping density $\left(D_{n}=26 \mathrm{~cm}^{2} / \mathrm{s}, z=200 \mu \mathrm{m}, S_{f}=3\right.$ $\left.\times 10^{3} \mathrm{~cm} / \mathrm{s}\right)$.

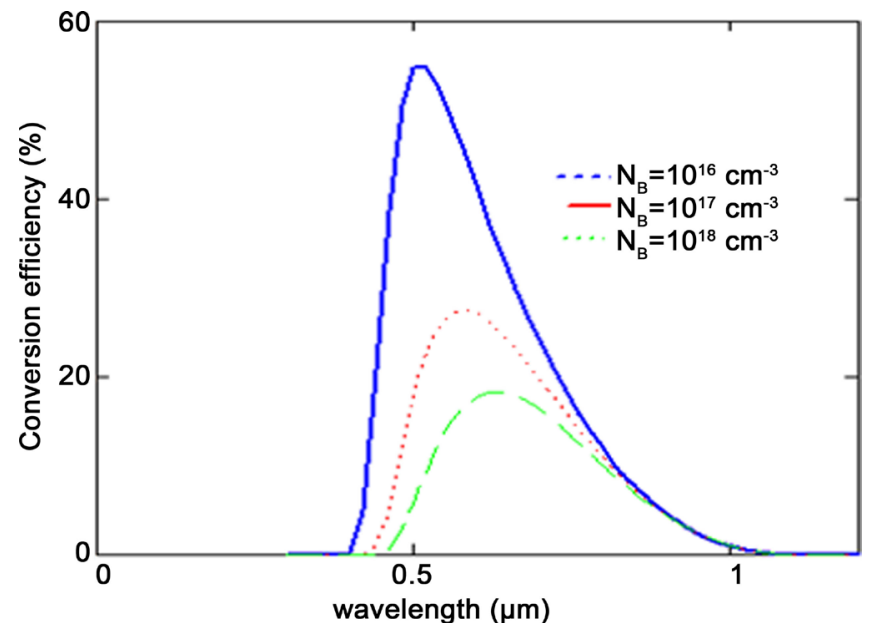

Figure 6. Conversion efficiency versus wavelength for various base doping densities $\left(D_{n}\right.$ $\left.=26 \mathrm{~cm}^{2} / \mathrm{s}, Z=200 \mu \mathrm{m}, S_{f}=5 \times 10^{5} \mathrm{~cm} / \mathrm{s}\right)$.

This result has been predicted previously but the difficulty is that the exact profile of the maximum power versus base doping density was not known. This blank is now filled for vertical parallel junction solar cells.

\subsection{Internal Quantum Efficiency}

The internal quantum efficiency of the VMJ cell has also been evaluated for various illumination wavelengths and different base doping densities on Figure 6.

This figure shows that VMJ solar cell's conversion efficiency increases with illumination wavelength between $0.3 \mu \mathrm{m}$ to a certain threshold $\lambda_{s}$ from which it began decreasing. This is due to the manner light is absorbed in the semiconductor material by Beer-Lambert law and the dependence of the absorption coefficient to the illumination wavelength. We can also observe the shifting effect of base doping density on the threshold point with a net decrease of the conversion efficiency maximum and shrinkage of the conversion efficiency bandwidth. 


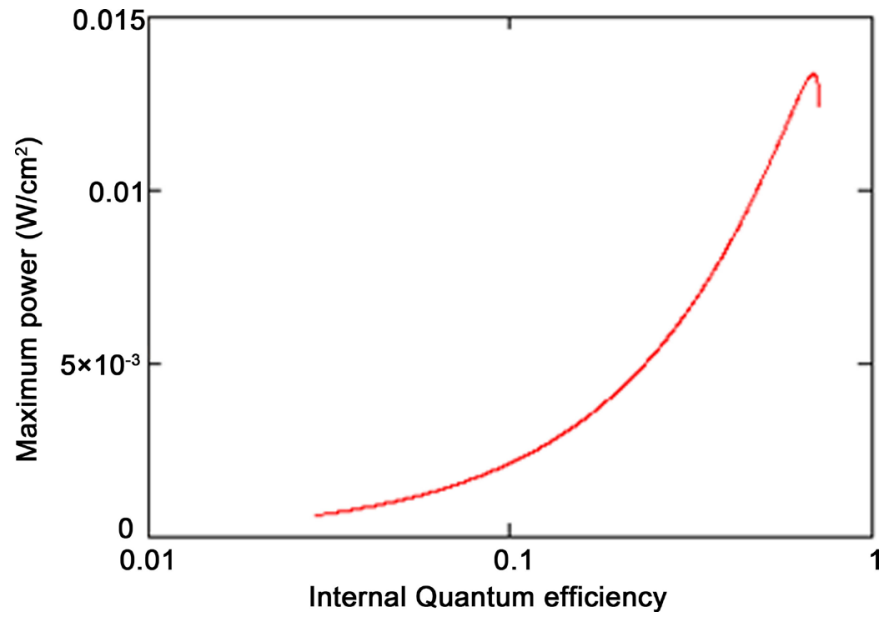

Figure 7. Maximum power versus base doping density $\left(D_{n}=26 \mathrm{~cm}^{2} / \mathrm{s}, Z=200 \mu \mathrm{m}, S_{f}=5\right.$ $\left.\times 10^{5} \mathrm{~cm} / \mathrm{s}\right)$.

We then see the importance of doping density on the VMJ solar cell performance.

We want to know now how the maximum output power is related to the internal quantum efficiency; we then plotted the maximum output power versus internal quantum efficiency in Figure 7.

This figure shows that the output power increases with increasing internal quantum efficiency. Given that internal quantum efficiency is the fraction of collected electron/hole pairs per photon of wavelength that enters the solar cell, an increase in IQE mean that there are more and more collected electron/hole pairs and more collected electron/hole pairs also means more generation and then more power.

\section{Conclusions}

In this paper, we have presented a theoretical investigation of a vertical parallel junction silicon solar cell under monochromatic illumination. We showed how internal quantum efficiency is related to the illumination wave-length and the decreasing effect of the base doping density on this quantum efficiency. We presented for the first time, to the best of our knowledge, the dependency of the maximum output power on the internal quantum efficiency of the vertical junction solar cell.

The dependency profile of the maximum output power versus the base doping density shows a base doping density limit from which the maximum power decreases are in agreement with other works.

\section{References}

[1] APS News. This Month in Physics History (2009) April 25, 1954: Bell Labs Demonstrates the First Practical Silicon Solar Cell. http://www.aps.org/publications/apsnews/200904/physicshistory.cfm

[2] Gover, A. and Stella, P. (1974) Vertical Multijunction Solar-Cell One-Dimensional Analysis. IEEE Transactions on Electron Devices, ED-21:6, 351-356. 
https://doi.org/10.1109/T-ED.1974.17927

[3] Xing, Y., Han, P., Wang, S., Fan, Y., Liang, P., Ye, Z., Li, X., Hu, S., Lou, S., Zhao, C. and Mi, Y. (2013) Performance Analysis of Vertical Multi-Junction Solar Cell with Front Surface Diffusion for High Concentration. Solar Energy, 94, 8-18. https://doi.org/10.1016/j.solener.2013.04.030

[4] Sarfaty, R., Cherkun, A., Pozner, R., Segev, G., Zeierman, E., Flitsanov, Y., Kribus, A. and Rosenwaks, Y. (2012) Vertical Junction Si Micro-Cells for Concentrating Photovoltaics. Progress in Photovoltaics. Research and Applications, 20, 197-208. https://doi.org/10.1002/pip.1118

[5] Terheiden, B., Hahn, G., Fath, P. and Bucher, E. (2000) The Lamella Silicon Solar Cell. Proceedings of the 16th European Photovoltaic Solar Energy Conference, Glasgow, 1-5 May 2000, 1377-1380.

[6] Ayvazyan, G.E., Kirakosyan, G.H. and Minasyan, G.A. (2004) Characteristics of Solar Cells with Vertical P-N Junction. Proceedings of the 19th European Photovoltaic Solar Energy Conference, Paris, 7-11 June 2004, 117-119.

[7] Franklin, E., Blakers, A. and Everett, V. (2009) Sliver Solar Cells for Concentrator PV Systems with Concentration Ratio below 50. Progress in Photovoltaics: Research and Applications, 17, 403-418. https://doi.org/10.1002/pip.896

[8] Mathieu, H. and Fanet, H. (2009) Physique des Semi-Conducteurs et des Composants électroniques. 6th Edition, Dunod, France.

[9] Heinbockel, J.H. (1986) Summary of Mathematical Models for a Conventional and Vertical Junction Photoconverter. NASA-CR-177144 Progress Report, NASA, Washington DC.

[10] Green, M.A. (2008) Self-Consistent Optical Parameters of Intrinsic Silicon at $300 \mathrm{~K}$ Including Temperature Coefficients. Solar Energy Materials and Solar Cells, 92, 1305-1310. https://doi.org/10.1016/j.solmat.2008.06.009

[11] Liou, J.J. and Wong, W.W. (1992) Comparison and Optimization of the Performance of Si and GaAs Solar Cells. Solar Energy Materials and Solar Cells, 28, 9-28. https://doi.org/10.1016/0927-0248(92)90104-W

\section{Submit or recommend next manuscript to SCIRP and we will provide best service for you:}

Accepting pre-submission inquiries through Email, Facebook, LinkedIn, Twitter, etc. A wide selection of journals (inclusive of 9 subjects, more than 200 journals)

Providing 24-hour high-quality service

User-friendly online submission system

Fair and swift peer-review system

Efficient typesetting and proofreading procedure

Display of the result of downloads and visits, as well as the number of cited articles

Maximum dissemination of your research work

Submit your manuscript at: http://papersubmission.scirp.org/

Or contact ojapps@scirp.org 